\title{
Sleep-Disordered Breathing in Patients with Heart Failure
}

\author{
Winfried Randerath ${ }^{1} \cdot$ Shahrokh Javaheri ${ }^{2}$
}

Published online: 25 April 2016

(C) Springer International Publishing AG 2016

\begin{abstract}
Breathing disturbances during sleep play a significant role in patients with cardiac diseases due to their high prevalence and impact on outcome. Obstructive sleep apnea (OSA) is a major risk factor of arterial hypertension and is associated with atrial fibrillation. A majority of heart failure (HF) patients suffer from OSA or central sleep apnoea (CSA), both associated with impaired prognosis. The application of continuous positive airway pressure has proven to improve symptoms and outcome in severe OSA. However, optimal therapy of CSA in heart failure is under discussion. Adaptive servoventilation (ASV) allows for counterbalancing the shift between hyperventilation and hypoventilation in periodic breathing. It has been shown to be superior to oxygen, continuous positive airway pressure therapy (CPAP) or other therapeutical options in HF patients with CSA. However, due to recent data, its use should be adapted closely to current indications and contraindications.
\end{abstract}

Keywords Sleep breathing disorders · Obstructive sleep apnea $\cdot$ OSA $\cdot$ Heart failure $\cdot$ Central sleep apnoea $\cdot$ Adaptive servoventilation

This article is part of the Topical Collection on Sleep Related Breathing Disorders

Winfried Randerath

Randerath@klinik-bethanien.de

1 Clinic of Pneumology and Allergology, Center for Sleep Medicine and Respiratory Care, Bethanien Hospital, Solingen, Germany

2 Sleep Physician, Sleep Center, Bethesda North Hospital, Cincinnati, OH, USA

\section{Introduction}

Breathing disturbances during sleep on one hand and heart failure (HF) on the other are associated in a bidirectional relationship. Obstructive sleep apnea (OSA) has been identified as an important risk factor of arterial hypertension, stroke, HF and arteriosclerosis. At least $50 \%$ of HF patients present with varying combinations of sleep-related breathing disturbances (SRBDs), predominantly central sleep apnea (CSA) and Hunter-Cheyne-Stokes breathing (HCSB) [1]. There is a broad consensus to recommend continuous positive airway pressure therapy (CPAP) in OSA with and without HF aiming at the improvement of daytime sleepiness, neurocognitive deficits and risk of accidents, but also to improve oxygenation and sympathetic activity and therefore reduce cardiovascular consequences. However, recent months were characterized by an intensive and controversial discussion about the indication and optimal treatment of CSA/HCSB in HF patients.

\section{Obstructive Sleep Apnea}

Moderate to severe OSA, as defined by a number of $\geq 15$ apneas or hypopneas per hour of sleep, reaches a prevalence of $17 \%$ in men and $9 \%$ in women between 30 and 70 years of age [2]. The obstructive events are associated with repetitive oxygen desaturations and reoxygenations, brief increases of the carbon dioxide $\left(\mathrm{CO}_{2}\right)$ partial pressure and arousals from sleep. Breathing effort and work of breathing increase during the upper airway obstruction until the event terminates abruptly. The immense chemical and mechanical stress of the respiratory system is associated with an overnight increase of the sympathetic and a decrease of parasympathic activity [3-11]. The numerous shifts between hypoxia and reoxygenation, the production of reactive oxygen species and the blood gas alterations increase muscle sympathetic nerve activity, blood 
pressure, vascular resistance, endothelial dysfunction and arteriosclerosis $[3,5,12,13]$. Therefore, OSA represents a risk factor for arterial hypertension and vascular diseases, independent of known confounders [9, 10, 14-16].

Most studies on the association of SRBD in heart failure focus on patients with reduced left ventricular ejection fraction (HFrEF), i.e. systolic dysfunction. However, the consequences of OSA, especially arterial hypertension, may also contribute to the development of diastolic HF. This is characterized by preserved left ventricular ejection fraction (HFpEF) but increased end-diastolic left ventricular pressure and consecutive pulmonary fluid overload $[4,8-10,17]$. As noted, OSA is also associated with coronary artery disease, stroke and - as a consequence of the cardiovascular morbidity - increased mortality. Survival is significantly impaired in patients with an $\mathrm{AHI} \geq 30 / \mathrm{h}[15,16,18-24]$.

Treatment of OSA focuses at the abolishment of underlying predisposing factors, which increase the pressure of the surrounding tissue, e.g. fat or fluid accumulation. However, upper airway obstruction has to be counterbalanced by elevating the intraluminal pressure with positive airway pressure (PAP) treatment in the majority of patients [13]. Several studies have demonstrated that PAP may reverse remodelling of myocardial structure $[8,10,25]$. CPAP has been shown to improve survival in observational studies [21, 26]. Javaheri et al. analysed more than 30,000 data sets of newly diagnosed HF patients. They showed a significant improvement of survival in those patients diagnosed and treated for sleep apnea as compared to those with sufficient but undiagnosed and untreated breathing disturbances [27]. Mandibular advancement devices (MADs) have proven to reduce obstructive SRBD significantly but less efficacious as compared to PAP therapy. Although measures of daytime sleepiness and quality of life have shown similar results with MADs and PAP, compliance data are in favour of oral appliances. However, more data on cardiovascular outcome parameters are needed. Taking these aspects together, CPAP is the treatment of choice in HF patients with predominant OSA. However, so far, there are no randomized clinical trials showing any beneficial outcome, such as improved quality of life, decreased hospitalization and improved survival.

\section{Central Sleep Apnea and Hunter-Cheyne-Stokes Breathing}

Recurrent cessations or reductions of airflow with simultaneous proportional reduction of breathing effort characterize CSA [13, 28, 29]. The term Hunter-Cheyne-Stokes breathing describes the pattern of periodic breathing in HF patients [28-30]. Central disturbances generate from reduced, lacking or overshooting and undershooting generation of the ventilatory impulses from the peripheral and central chemoreceptors. Central apneas with HCSB characteristically have a long cycle, typically $40 \mathrm{~s}$ or more. However central apneas, without the prolonged cycle time, are also observed during sleep with exposure to high altitude, with brainstem lesions, stroke, endocrine disorders and use of opioids [31-36]. However, cardiovascular diseases are by far the most relevant causes of central disturbances, especially HF and atrial fibrillation [30-32, 37-40].

The pathophysiology of OSA is based on narrowing and occlusion of the upper airways, and multiple mechanisms are involved. In HF patients with HCSB, central apneas are best explained by an increase in loop gain, with several characteristics including increased chemoresponsiveness resulting in shift between hypoventilation and hyperventilation with overshooting and undershooting of the ventilation and the pattern of periodic breathing [32, 37, 41-45]. The instability of the respiration is aggravated by changes of the reactivity of cerebral vessels and also by arousals from sleep.

\section{Treatment of Central Sleep Apnea}

Prior to specific treatment of central SRBD, therapy of the underlying cardiac disorders should be re-evaluated critically. Interventional treatment of coronary or valvular diseases, electrotherapy of bradyarrhythmias or tachyarrhythmias and pharmaceutical therapies according to current guidelines remain the cornerstones of care of HF patients. However, patients with remaining CSA/HCSB may require additional therapies after optimizing conventional options. Sufficient data showing a survival benefit in these patients treated with PAP therapy based on large, long-term randomized controlled trials are lacking. However, if a patient suffers from daytime sleepiness, neurocognitive deficits and impaired quality of sleep, specific treatment may be justified.

\section{Oxygen}

The application of oxygen improves oxygen supply to cardiac and respiratory muscle cells and thus improves their efficacy. Moreover, oxygen reduces the hypoxic and hypercapnic respiratory drive which - theoretically - may dampen the increased loop gain and the ventilatory overshoot and undershoot. However, large, long-term trials on the efficacy of oxygen in HF with CSA/HCSB are not available [46]. Administration of supplemental nasal oxygen reduces the number of respiratory disturbances by $50 \%$ [46-49]. In a randomized, but open clinical trial of 12-week duration, Sasayama et al. [49] described significant improvement not only in SRBD but also in cardiac function and quality of life. This was confirmed in another small study [48] of 3-month duration which in addition showed diminution in cardiac sympathetic turnover. Previously, another study reported a decrease in urinary norepinephrine [47]. Large randomized controlled trials on the oxygen therapy are badly needed, 
particularly in view of the failure of the SERVE-HF trial discussed below.

\section{Drug Therapy}

The respiratory stimulants theophylline and acetazolamide are discussed in the treatment of CSA/HCSB [50-55]. Javaheri et al. performed a randomized controlled study on the efficacy of oral theophylline as compared to placebo in 15 stable patients with HFrEF and showed a $50 \%$ reduction of the AHI. However, due to lacking long-term data and the arrythmogenic potency of the drug, it should only be reserved for selected cases under close supervision.

Acetazolamide was studied in two small placebocontrolled trials $[41,55]$. Both studies showed a reduction of respiratory disturbances between 44 and $50 \%$. Interestingly, acetazolamide increased the hypercapnic ventilatory response significantly [41], which indicates an increased loop gain. The authors concluded that this rise in HCVR may be responsible for the incomplete resolution of central breathing disturbances during sleep.

\section{Positive Airway Pressure Treatment}

The application of PAP potentially improves SRBD in HF in several ways:

1. It stabilizes and reopens occluded upper airways.

2. It reduces the work of breathing.

3. It improves ventilation of non-ventilated lung compartments.

4. It improves the matching of ventilation and perfusion.

5. It reduces the left ventricular afterload and left ventricular function in volume-overloaded HF patients.

As a result, several clinical trials have shown improvements of the left ventricular ejection fraction under CPAP in HF patients [56-67]. However, survival benefit has not convincingly been described in large prospective randomized studies $[68,69]$. The Canadian continuous positive airway pressure (CanPAP) trial studied the effect of additional CPAP in $258 \mathrm{HF}$ patients with severely reduced left ventricular ejection fraction and CSA on survival, respiratory disturbances and surrogate parameters. CPAP therapy over a mean of 2 years was associated with significant improvements in apneas and hypopneas, oxygen saturation, ejection fraction, norepinephrine levels and exercise performance. However, the study failed to show a significant difference in survival without heart transplantation. Interestingly, survival was superior in the control group during the first 18 months of therapy but was overtaken by CPAP during the last study period [70]. Moreover, the effect of CPAP on respiratory disturbances varied substantially. CPAP reduced the AHI by $50 \%$ in mean.
Arzt et al. performed a post hoc analysis of the CanPAP data and found a substantially better improvement in CPAP responders as compared to non-responders. However, as this analysis was not predefined, the positive results should be interpreted cautiously. For example, one can speculate that the coincidence of CPAP response and better survival is not a causal relationship but a marker of a specific phenotype [71]. Nevertheless, the first step in the therapeutical approach to symptomatic HF patients with $\mathrm{CSA} / \mathrm{HCSB}$ is a CPAP trial. If effective, CPAP is advantageous due to its simplicity, lower costs and brought availability.

\section{Adaptive Servoventilation}

Taking the data on oxygen, drugs and CPAP together, none of the available therapies improved CSA/HCSB sufficiently. However, optimal reduction of breathing disturbances during sleep seems to be a precondition to improve outcome [71]. Adaptive servoventilation (ASV, also called auto servoventilation, anti-cyclic modulated ventilation) has been designed to counterbalance the pathological breathing pattern of hyperventilation and hypoventilation and to avoid central apneas. Commonly, the available ASV devices anti-cyclically adapt pressure support (i.e. the difference between inspiratory and expiratory pressure) to the patient ventilation. During periods of hyperventilation, pressure support is reduced; during hypoventilation, it is increased. Thus, the algorithms avoid hypocapnia on one hand and hypercapnia and hypoxia on the other. As a consequence, the stabilization of the respiration reduces the hypercapnic ventilatory response, which is one factor of the underlying pathophysiology [72]. The algorithms apply mandatory breaths in case of central apneas. The expiratory pressure (EPAP) stabilizes the upper airways and can compensate for obstructive components. Devices from different manufacturers and different generations of ASV algorithms differ in target parameters, sensing of the ventilatory parameters and pattern of reaction. The main differences between older and more recent devices include the application of the automatic EPAP and improvement in pressure support during inspiration. While the first generations applied a fixed EPAP predefined by the investigator, current versions use automatic adaptation of the EPAP according to the varying level of upper airway obstruction. This allows stabilizing the upper airways with the minimal required pressure level. Moreover, the first ASV devices applied a minimal pressure support of 3 mbar during inspiration. As a consequence, all patients were ventilated to some extent even in periods of hyperventilation. In contrast, the actual algorithms apply pressure support only during periods of reduced flow or minute ventilation but zero tidal volume during hyperventilation. Thirdly, the new generation device has improved algorithm for how the dynamics of inspiratory pressure support may change. This has become 
relevant in the discussion of the Adaptive Servo-Ventilation for Central Sleep Apnea in Systolic Heart Failure (SERVEHF) trial (see below) [73-76].

ASV devices are often used in patients with coexisting obstructive and central sleep apnea and several phenotypes of central breathing disturbances including treatment emergent CSA, opioid induced CSA, CSA due to high altitude and primary CSA [77-81]. Although the scientific evidence for several of these situations is limited, data from cohort studies, follow-up series and some randomized controlled trials demonstrated the efficacy of ASV and its superiority to other treatment options, including oxygen, CPAP, bilevel PAP in spontaneous timed mode (BPAP-ST) [25, 56, 82, 83]. Teschler et al. applied different therapeutical options $\left(\mathrm{O}_{2}\right.$, CPAP, BPAP-ST, ASV) randomly for one night each. They used a first generation ASV device and found a significantly better improvement and normalization of central apneas under ASV as compared to the other options [51]. Pepperell et al. compared therapeutic and subtherapeutic ASV for 1 month in heart failure with reduced ejection fraction and CSA/HCSB. ASV sufficiently improved not only breathing disturbances and parameters of daytime sleepiness but also cardiac surrogate parameters, while subjective sleepiness did not change [53]. ASV has been shown to be superior to CPAP in heart failure patients with coexisting obstructive and central sleep apnea $[30,80,81,84]$. Takayama et al. found an improvement of the 1-year survival rate in ASV-treated patients using their devices for more than $4 \mathrm{~h} /$ night.

Encouraged by the positive effects of ASV on respiratory disturbances during sleep, left ventricular ejection fraction, cardiac surrogate parameters and quality of life, two large, multinational, prospective, randomized controlled trials (SERVE-HF, adaptive servoventilation for therapy of central and OSA in HF trial (ADVENT-HF)) were initiated [1, 25, 53, 85-88]. The SERVE-HF trial included 1325 patients with symptomatic chronic HF (NYHA grades II-IV) with left ventricular ejection fraction $\leq 45 \%$ and predominant CSA. Patients were randomized to treatment with or without ASV in addition to optimized conventional cardiac therapy. According to the design, the study was terminated when the predefined number of 651 cardiovascular events was exceeded. The combined primary endpoint included all-cause mortality, hospitalizations, decompensation of HF, heart transplantation and events of sudden cardiac death. While the primary endpoint did not differ significantly between the two groups, further analyses showed increased rates of death from any cause and cardiovascular death in the ASV group. Moreover, ASV failed to show beneficial effects on cardiac or quality of life parameters in SERVE$\mathrm{HF}$ in contrast to previous findings.

The SERVE-HF trial has led to immediate reactions of the companies manufacturing ASV devices and also from health authorities. They advised sleep physicians not to use ASV in patients with symptomatic systolic HF with $\mathrm{EF}<45 \%$ and predominant CSA. Nevertheless, several concerns have been raised (for details, see reference 78 ) regarding the trial and the interpretation of the results:

1. Of randomized patients, $23 \%$ crossed over from one to the other treatment arm; 98 of 578 patients randomized to the control group started different types of positive airway pressure therapy (mostly ASV); 168 of 583 patients randomized to ASV discontinued treatment.

2. Compliance rate in the ASV group was very low with a mean average usage of $3.7 \mathrm{~h} /$ night. Of the patients, $27 \%$ used their devices less than $1 \mathrm{~h} / \mathrm{night} ; 40 \%$ of the patients used their devices less than $3 \mathrm{~h} /$ night.

3. There was a significant higher usage of anti-arrhythmic drugs in the ASV group as compared to controls. This might be clinically relevant as anti-arrhythmic drugs themselves may destabilize cardiac cells. It may also indicate more sensitive patient phenotypes.

4. Subanalyses of the study showed mortality rates only in patients with high usage of anti-arrhythmic drugs and in patients with a left ventricular ejection fraction $<30 \%$.

5. Diagnosis of sleep apnea and differentiation of respiratory events were based mostly on polygraphy. Obviously, due to missing neurologic parameters, polygraphy cannot detect sleep-wake transitions or events during wakefulness. This leads to misinterpretation of respiratory disturbances which can influence inclusion of the patients.

6. The investigators used an older version of the ASV devices with fixed expiratory pressure and a minimal pressure support of $3 \mathrm{~cm} \mathrm{H}_{2} \mathrm{O}$. Therefore, patients were ventilated even in periods without any need of ventilatory support which may lead to hypocapnia and electrolyte imbalance.

Unfortunately, the investigators presented only the intention-to-treat analysis by now. However, having the high crossover between the treatment arms and the low compliance rate in mind, the per-protocol analysis would be of crucial importance. If ASV was indeed the cause of the increased mortality, one would expect the poorest outcome in those patients who used the devices according to the protocol and achieved best compliance rates. For more detailed discussion, the interested reader is referred to reference 78 .

Meanwhile, the 'ADVENT-HF' is being continued after an independent board performed an interim analysis of the safety data. ADVENT-HF differs from SERVE-HF in several aspects: It uses a more recent ASV version from another manufacturer, which allows variable adaptation of the expiratory pressure and also a zero pressure support. Thus, the risk of overtreatment is minimized. Inclusion is based on polysomnography and core-lab evaluation of all studies. The majority of patients included today suffer from HF with nonhypersomnolent OSA, while one third suffers from CSA. 
Cowie et al. discussed if the elimination of CSR might be unfavourable in HF patients and be responsible for the excess mortality [89]. These considerations are based on Naughton's hypothesis that CSR might be a compensatory mechanism of the failing heart [90]. Data from animal trials, mathematical models and studies in healthy persons indicated that high tidal volume and high positive end-expiratory pressure in CSR might improve lung ventilation and blood oxygenation and reduce work of breathing (with central apnea), sympathetic activity and cardiac mechanics. However, the application of positive airway pressure has similar effects: PAP has been shown to stabilize upper airways and increase alveolar pressure, prevent collapse of small airways, improve pulmonary ventilation and reopen atelectasis. It is associated with fluid shift from alveoli and interstitial space into pulmonary vessels, improve fluid overload in the lung and lung oedema. As a consequence, PAP improves functional residual capacity, gas exchange and oxygenation [91-99]. Moreover, positive effects of PAP therapy on work of breathing and ASV on sympathetic activity have been shown. PAP reduces cardiac output in healthy persons and volume-depleted HF patients. In contrast, PAP improves left ventricular transmural pressure and stroke volume in volume-overloaded HF patients [100, 101]. In addition, the number of respiratory disturbances (both, obstructive and central) correlates with the pulmonary capillary wedge pressure and the fluid shift from the lower to the upper body compartments $[37,62]$.

\section{Alternative Hypotheses for the Excess Mortality}

Patients with substantially reduced left ventricular ejection fraction who are additionally treated with anti-arrhythmic drugs and diuretics are at high risk of life-threatening cardiac events. As discussed before, the application of PAP may reduce cardiac function in volume-depleted HF patients. It cannot be excluded that an undefined number of patients in SERVE-HF were overtreated with diuretics leading to increased sensitivity to pressure application.

Several factors may destabilize the clinical situation of the high-risk population (NYHA III-IV, II with hospitalization, anti-arrhythmic therapy, severely impaired heart function) and impaire the prognosis of these patients. The acid base balance can be influenced by the use of diuretics, leading to metabolic alkalosis, and by both extremes of ventilation. Chronic hyperventilation is associated with respiratory alkalosis, while hypoventilation with retention of $\mathrm{CO}_{2}$ is compensated by metabolic alkalosis. These acid base imbalances are known arrythmogenic factors. On one hand, the application of a fixed expiratory pressure (in the older ASV versions) may have led to hypoventilation by insufficiently stabilizing upper airways. On the other hand, these devices inevitably apply a minimal pressure support of $3 \mathrm{~cm} \mathrm{H}_{2} \mathrm{O}$ during inspiration, ventilate patients mechanically even in situations of stable respiration and thus potentially induce hyperventilation and alkalosis.

\section{Conclusions}

The association between sleep-disordered breathing and heart failure is a major clinical problem due to the high prevalence and the impact on morbidity and prognosis. OSA is a major risk factor for cardiovascular diseases and should be treated primarily with positive airway pressure in order to improve quality of life and outcome of affected patients. Heart failure is the most frequent cause of central breathing disturbances including Hunter-Cheyne-Stokes breathing. Based on the results of the SERVE-HF trial, patients' history, the polysomnographic pattern and cardiac function findings have to be evaluated precisely to optimally stratify the therapeutical algorithm. There is no prognostic rationale to treat asymptomatic heart failure patients with CSA/HCSB. However, treatment may be indicated if patients suffer from daytime sleepiness, neurocognitive deficits, fatigue and other sleep-related limitations. Heart failure patients with preserved left ventricular affection (ejection fraction $\geq 45 \%$ ) can undergo a trial of CPAP or - if it fails - adaptive servoventilation. In contrast, ASV is contraindicated in patients with predominant $\mathrm{CSA} / \mathrm{HCSB}$ if the LVEF is $>45 \%$. These patients should only be treated in clinical trials, such as ADVENT-HF, as no recommendations for clinical practice can be given at this moment. The limitations of SERVE-HF underline the necessity of further trials with ASV, oxygen and newer treatment modalities, such as phrenic nerve stimulation.

Acknowledgments The authors would like to thank Carla Miltz for her effort and support in completing this manuscript.

\section{Compliance with Ethical standards}

Conflict of Interest Winfried Randerath has received personal fees from Resmed, Inspire, Heinen \& Löwenstein and Philips Respironics.

Shahrokh Javaheri has received honoraria for speaking from Philips Respironics and Resmed. He is on advisory board of Respircardia and Leve Nova.

Human and Animal Rights and Informed Consent This article does not contain any studies with human or animal subjects performed by any of the authors.

\section{References}

1. Brack T, Randerath W, Bloch KE. Cheyne-stokes respiration in patients with heart failure: prevalence, causes, consequences and treatments. Respiration. 2012;83(2):165-76. 
2. Peppard PE, Young T, Barnet JH, Palta M, Hagen EW, Hla KM. Increased prevalence of sleep-disordered breathing in adults. Am J Epidemiol. 2013;177(9):1006-14.

3. Nicholas W, Javaheri S. Pathophysiologic mechanisms of cardiovascular disease in obstructive sleep apnea. In: Javaheri S, Saunders W, editors. Sleep medicine clinics: sleep and cardiovascular disease. Philadelphia: Elsevier; 2007. p. 539-47.

4. Somers V, Javaheri S. Cardiovascular effects of sleep-related breathing disorders. Principles and practices of sleep medicine. 5th ed. St. Louis: Elsevier; 2011. p. 1370-80.

5. Gilmartin GS, Lynch M, Tamisier R, Weiss JW. Chronic intermittent hypoxia in humans during 28 nights results in blood pressure elevation and increased muscle sympathetic nerve activity. Am J Physiol Heart Circ Physiol. 2010;299(3):H925-31.

6. Peppard PE, Young T, Palta M, Skatrud J. Prospective study of the association between sleep-disordered breathing and hypertension. N Engl J Med. 2000;342(19):1378-84.

7. Young T, Nieto J, Javaheri S. Systemic and pulmonary hypertension in obstructive sleep apnea. In: Kryger M, Roth T, Dement W, Saunders W, editors. Principles and practices of sleep medicine. Philadelphia: Elsevier; 2008. p. 1381-92.

8. Javaheri S. Sleep dysfunction in heart failure. Curr Treat Options Neurol. 2008;10(5):323-35.

9. Arias MA, Garcia-Rio F, Alonso-Fernandez A, Mediano O, Martinez I, Villamor J. Obstructive sleep apnea syndrome affects left ventricular diastolic function: effects of nasal continuous positive airway pressure in men. Circulation. 2005;112(3):375-83.

10. Shivalkar B, Van de Heyning C, Kerremans M, Rinkevich D, Verbraecken J, De Backer W, et al. Obstructive sleep apnea syndrome: more insights on structural and functional cardiac alterations, and the effects of treatment with continuous positive airway pressure. J Am Coll Cardiol. 2006;47(7):1433-9.

11. Nieto FJ, Young TB, Lind BK, Shahar E, Samet JM, Redline S, et al. Association of sleep-disordered breathing, sleep apnea, and hypertension in a large community-based study. Sleep Heart Health Stud JAMA. 2000;283(14):1829-36.

12. Garvey JF, Taylor CT, McNicholas WT. Cardiovascular disease in obstructive sleep apnoea syndrome: the role of intermittent hypoxia and inflammation. Eur Respir J. 2009;33(5):1195-205.

13. Randerath W. Sleep and heart. In: Chokroverty S, Ferini-Strambi L, editors. Sleep and its disorders. Oxford: Oxford University Press; 2016. in Press.

14. Arzt M, Young T, Finn L, Skatrud JB, Bradley TD. Association of sleep-disordered breathing and the occurrence of stroke. Am J Respir Crit Care Med. 2005;172(11):1447-51.

15. Redline S, Yenokyan G, Gottlieb DJ, Shahar E, O'Connor GT, Resnick HE, et al. Obstructive sleep apnea-hypopnea and incident stroke: the sleep heart health study. Am J Respir Crit Care Med. 2010;182(2):269-77.

16. Johnson KG, Johnson DC. Frequency of sleep apnea in stroke and TIA patients: a meta-analysis. J Clin Sleep Med: JCSM: Off Publ Am Acad Sleep Med. 2010;6(2):131-7.

17. Bitter T, Faber L, Hering D, Langer C, Horstkotte D, Oldenburg O. Sleep-disordered breathing in heart failure with normal left ventricular ejection fraction. Eur J Heart Fail. 2009;11(6):602-8.

18. Duran J, Esnaola S, Rubio R, Iztueta A. Obstructive sleep apneahypopnea and related clinical features in a population-based sample of subjects aged 30 to 70 yr. Am J Respir Crit Care Med. 2001;163(3 Pt 1):685-9.

19. Peker Y, Hedner J, Kraiczi H, Loth S. Respiratory disturbance index: an independent predictor of mortality in coronary artery disease. Am J Respir Crit Care Med. 2000;162(1):81-6.

20. Yumino D, Tsurumi Y, Takagi A, Suzuki K, Kasanuki H. Impact of obstructive sleep apnea on clinical and angiographic outcomes following percutaneous coronary intervention in patients with acute coronary syndrome. Am J Cardiol. 2007;99(1):26-30.
21. Marin JM, Carrizo SJ, Vicente E, Agusti AG. Long-term cardiovascular outcomes in men with obstructive sleep apnoeahypopnoea with or without treatment with continuous positive airway pressure: an observational study. Lancet. 2005;365(9464):1046-53.

22. Punjabi NM, Caffo BS, Goodwin JL, Gottlieb DJ, Newman AB, O'Connor GT, et al. Sleep-disordered breathing and mortality: a prospective cohort study. PLoS Med. 2009;6(8), e1000132.

23. Young T, Finn L, Peppard PE, Szklo-Coxe M, Austin D, Nieto FJ, et al. Sleep disordered breathing and mortality: eighteen-year follow-up of the Wisconsin sleep cohort. Sleep. 2008;31(8):1071-8.

24. Khayat R, Jarjoura D, Porter K, Sow A, Wannemacher J, Dohar R, et al. Sleep disordered breathing and post-discharge mortality in patients with acute heart failure. Eur Heart J. 2015;36(23):1463-9.

25. Randerath WJ, Nothofer G, Priegnitz C, Anduleit N, Treml M, $\mathrm{Kehl} \mathrm{V}$, et al. Long-term auto servo-ventilation or constant positive pressure in heart failure and co-existing central with obstructive sleep apnea. Chest. 2012;142(2):440-7.

26. Buchner NJ, Sanner BM, Borgel J, Rump LC. Continuous positive airway pressure treatment of mild to moderate obstructive sleep apnea reduces cardiovascular risk. Am J Respir Crit Care Med. 2007;176(12):1274-80.

27. Javaheri S, Caref EB, Chen E, Tong KB, Abraham WT. Sleep apnea testing and outcomes in a large cohort of Medicare beneficiaries with newly diagnosed heart failure. Am J Respir Crit Care Med. 2011;183(4):539-46.

28. Dowdell WT, Javaheri S, McGinnis W. Cheyne-Stokes respiration presenting as sleep apnea syndrome. Clinical and polysomnographic features. Am Rev Respir Dis. 1990;141(4 Pt 1):871-9.

29. Badr MS, Toiber F, Skatrud JB, Dempsey J. Pharyngeal narrowing/occlusion during central sleep apnea. J Appl Physiol. 1995;78(5):1806-15.

30. Javaheri S. Heart Failure. In: Kryger M, Roth T, Dement W, editors. Principles and practices of sleep medicine. $\mathrm{d} / \mathrm{e}$ ed. Philadelphia: WB Saunders; 2011. p. 1400-15.

31. Javaheri S. Central sleep apnea. Clin Chest Med. 2010;31(2): 235-48.

32. Javaheri S, Dempsey JA. Central sleep apnea. Compr Physiol. 2013;3(1):141-63.

33. Cao M, Javaheri S. Chronic opioid use: effects on respiration and sleep. In: Tvildiani D, Gegechkori K, editors. Opioids pharmacology, clinical uses and adverse effects. New York: Nova Science Publishers, Inc; 2012. p. 1-13.

34. Javaheri S, Cao M. Opioid induced central sleep apnea. In: Fabiani $\mathrm{M}$, editor. Proceedings of the $\mathrm{X}$ world congress on sleep apnea, section: respiratory disorders and snoring. Turin: Edizioni Minerva Medica; 2012. p. 133-7.

35. Javaheri S, Parker TJ, Liming JD, Corbett WS, Nishiyama H, Wexler L, et al. Sleep apnea in 81 ambulatory male patients with stable heart failure. Types and their prevalences, consequences, and presentations. Circulation. 1998;97(21):2154-9.

36. Javaheri S, Parker TJ, Wexler L, Michaels SE, Stanberry E, Nishyama $\mathrm{H}$, et al. Occult sleep-disordered breathing in stable congestive heart failure. Ann Intern Med. 1995;122(7):487-92.

37. Solin P, Bergin P, Richardson M, Kaye DM, Walters EH, Naughton MT. Influence of pulmonary capillary wedge pressure on central apnea in heart failure. Circulation. 1999;99(12):1574-9.

38. Lanfranchi PA, Somers VK, Braghiroli A, Corra U, Eleuteri E, Giannuzzi P. Central sleep apnea in left ventricular dysfunction: prevalence and implications for arrhythmic risk. Circulation. 2003;107(5):727-32.

39. Nopmaneejumruslers C, Kaneko Y, Hajek V, Zivanovic V, Bradley TD. Cheyne-Stokes respiration in stroke: relationship to hypocapnia and occult cardiac dysfunction. Am J Respir Crit Care Med. 2005;171(9):1048-52. 
40. Javaheri S. Sleep disorders in systolic heart failure: a prospective study of 100 male patients. The final report. Int J Cardiol. 2006;106(1):21-8.

41. Javaheri S, Sands SA, Edwards BA. Acetazolamide attenuates hunter-cheyne-stokes breathing but augments the hypercapnic ventilatory response in patients with heart failure. Ann Am Thorac Soc. 2014;11(1):80-6.

42. Javaheri S, Corbett WS. Association of low PaCO2 with central sleep apnea and ventricular arrhythmias in ambulatory patients with stable heart failure. Ann Intern Med. 1998;128(3):204-7.

43. Randerath W. Central and mixed sleep-related breathing dirsorders. In: Barkoukis T, Matheson J, Ferber R, Doghramji $\mathrm{K}$, Blumer J, editors. Therapy in sleep medicine. Philadelphia: Elsevier; 2012. p. 243-53.

44. Javaheri S, Almoosa KF, Saleh K, Mendenhall CL. Hypocapnia is not a predictor of central sleep apnea in patients with cirrhosis. Am J Respir Crit Care Med. 2005;171(8):908-11.

45. Wilcox I, McNamara SG, Dodd MJ, Sullivan CE. Ventilatory control in patients with sleep apnoea and left ventricular dysfunction: comparison of obstructive and central sleep apnoea. Eur Respir J. 1998;11(1):7-13.

46. Aurora RN, Chowdhuri S, Ramar K, Bista SR, Casey KR, Lamm CI, et al. The treatment of central sleep apnea syndromes in adults: practice parameters with an evidence-based literature review and meta-analyses. Sleep. 2012;35(1):17-40.

47. Staniforth AD, Kinnear WJ, Starling R, Hetmanski DJ, Cowley AJ. Effect of oxygen on sleep quality, cognitive function and sympathetic activity in patients with chronic heart failure and CheyneStokes respiration. Eur Heart J. 1998;19(6):922-8.

48. Toyama T, Seki R, Kasama S, Isobe N, Sakurai S, Adachi H, et al. Effectiveness of nocturnal home oxygen therapy to improve exercise capacity, cardiac function and cardiac sympathetic nerve activity in patients with chronic heart failure and central sleep apnea. Circ J. 2009;73(2):299-304.

49. Sasayama S, Izumi T, Matsuzaki M, Matsumori A, Asanoi H, Momomura S, et al. Improvement of quality of life with nocturnal oxygen therapy in heart failure patients with central sleep apnea. Circ J. 2009;73(7):1255-62.

50. Javaheri S. CPAP should not be used for central sleep apnea in congestive heart failure patients. J Clin Sleep Med. 2006;2(4): 399-402.

51. Teschler H, Dohring J, Wang YM, Berthon-Jones M. Adaptive pressure support servo-ventilation: a novel treatment for CheyneStokes respiration in heart failure. Am J Respir Crit Care Med. 2001;164(4):614-9.

52. Koyama T, Watanabe H, Igarashi G, Terada S, Makabe S, Ito H. Short-term prognosis of adaptive servo-ventilation therapy in patients with heart failure. Circ J. 2011;75(3):710-2.

53. Pepperell JC, Maskell NA, Jones DR, Langford-Wiley BA, Crosthwaite N, Stradling JR, et al. A randomized controlled trial of adaptive ventilation for Cheyne-Stokes breathing in heart failure. Am J Respir Crit Care Med. 2003;168(9):1109-14.

54. Jilek C, Krenn M, Sebah D, Obermeier R, Braune A, Kehl V, et al. Prognostic impact of sleep disordered breathing and its treatment in heart failure: an observational study. Eur J Heart Fail. 2011;13(1):68-75

55. Takama N, Kurabayashi M. Effect of adaptive servo-ventilation on 1-year prognosis in heart failure patients. Circ J. 2012;76(3): 661-7.

56. Javaheri S, Harris N, Howard J, Chung E. Adaptive servoventilation for treatment of opioid-associated central sleep apnea. J Clin Sleep Med. 2014;10(6):637-43.

57. Ponikowski P, Javaheri S, Michalkiewicz D, Bart BA, Czarnecka D, Jastrzebski M, et al. Transvenous phrenic nerve stimulation for the treatment of central sleep apnoea in heart failure. Eur Heart J. 2012;33(7):889-94.

58. Skomro R, Silva R, Alves R, Figueiredo A, Lorenzi-Filho G. The prevalence and significance of periodic leg movements during sleep in patients with congestive heart failure. Sleep Breath. 2009;13(1):43-7.

59. Hanly PJ, Zuberi-Khokhar N. Periodic limb movements during sleep in patients with congestive heart failure. Chest. 1996;109(6):1497-502.

60. Guggisberg AG, Hess CW, Mathis J. The significance of the sympathetic nervous system in the pathophysiology of periodic leg movements in sleep. Sleep. 2007;30(6):755-66.

61. Pennestri MH, Montplaisir J, Colombo R, Lavigne G, Lanfranchi PA. Nocturnal blood pressure changes in patients with restless legs syndrome. Neurology. 2007;68(15):1213-8.

62. Yumino D, Redolfi S, Ruttanaumpawan P, Su MC, Smith S, Newton GE, et al. Nocturnal rostral fluid shift: a unifying concept for the pathogenesis of obstructive and central sleep apnea in men with heart failure. Circulation. 2010;121(14):1598-605.

63. Koo BB, Blackwell T, Ancoli-Israel S, Stone KL, Stefanick ML, Redline S, et al. Association of incident cardiovascular disease with periodic limb movements during sleep in older men: outcomes of sleep disorders in older men (MrOS) study. Circulation. 2011;124(11):1223-31.

64. Mirza M, Shen WK, Sofi A, Jahangir A, Mori N, Tajik AJ, et al. Frequent periodic leg movement during sleep is associated with left ventricular hypertrophy and adverse cardiovascular outcomes. J Am Soc Echocardiogr. 2013;26(7):783-90.

65. Javaheri S. Sleep in cardiovascular disease. In: CA K, editor. The encyclopedia of sleep. Academic Press: Waltham; 2013; pp. 557-562.

66. Arendt J, Bojkowski C, Franey C, Wright J, Marks V. Immunoassay of 6-hydroxymelatonin sulfate in human plasma and urine: abolition of the urinary 24-hour rhythm with atenolol. J Clin Endocrinol Metab. 1985;60(6):1166-73.

67. Lanfranchi PA, Pennestri MH, Fradette L, Dumont M, Morin CM, Montplaisir J. Nighttime blood pressure in normotensive subjects with chronic insomnia: implications for cardiovascular risk. Sleep. 2009;32(6):760-6.

68. Stoschitzky K, Sakotnik A, Lercher P, Zweiker R, Maier R, Liebmann $\mathrm{P}$, et al. Influence of beta-blockers on melatonin release. Eur J Clin Pharmacol. 1999;55(2):111-5.

69. Grandner MA, Sands-Lincoln MR, Pak VM, Garland SN. Sleep duration, cardiovascular disease, and proinflammatory biomarkers. Nat Sci Sleep. 2013;5:93-107.

70. Bradley TD, Logan AG, Kimoff RJ, Series F, Morrison D, Ferguson K, et al. Continuous positive airway pressure for central sleep apnea and heart failure. N Engl J Med. 2005;353(19):2025-33.

71. Arzt M, Floras JS, Logan AG, Kimoff RJ, Series F, Morrison D, et al. Suppression of central sleep apnea by continuous positive airway pressure and transplant-free survival in heart failure: a post hoc analysis of the Canadian Continuous Positive Airway Pressure for Patients with Central Sleep Apnea and Heart Failure Trial (CANPAP). Circulation. 2007;115(25):3173-80.

72. Oldenburg O, Bitter T, Lehmann R, Korte S, Dimitriadis Z, Faber $\mathrm{L}$, et al. Adaptive servoventilation improves cardiac function and respiratory stability. Clin Res Cardiol. 2011;100(2):107-15.

73. Javaheri S, Brown LK, Randerath WJ. Clinical applications of adaptive servoventilation devices: part 2. Chest. 2014;146(3): 858-68.

74. Javaheri S, Brown LK, Randerath WJ. Positive airway pressure therapy with adaptive servoventilation: part 1: operational algorithms. Chest. 2014;146(2):514-23.

75. Randerath W, Khayat R, Arzt M, Javaheri S. Missing links. Sleep Med. 2015;16(12):1495-6. 
76. Javaheri S, Brown LK, Randerath W, Khayat R. Serve-hf: more questions than answers. Chest. 2016;149(4):900-4.

77. Javaheri S, Malik A, Smith J, Chung E. Adaptive pressure support servoventilation: a novel treatment for sleep apnea associated with use of opioids. J Clin Sleep Med. 2008;4(4):305-10.

78. Brown L. Adaptive servo-ventilation for sleep apnea: technology, titration protocols, and treatment efficacy. Sleep Med Clin. 2010;5(3):419-37.

79. Javaheri S, Goetting MG, Khayat R, Wylie PE, Goodwin JL, Parthasarathy S. The performance of two automatic servoventilation devices in the treatment of central sleep apnea. Sleep. 2011;34(12):1693-8.

80. Randerath WJ, Galetke W, Stieglitz S, Laumanns C, Schafer T. Adaptive servo-ventilation in patients with coexisting obstructive sleep apnoea/hypopnoea and Cheyne-Stokes respiration. Sleep Med. 2008;9(8):823-30.

81. Randerath WJ, Galetke W, Kenter M, Richter K, Schafer T. Combined adaptive servo-ventilation and automatic positive airway pressure (anticyclic modulated ventilation) in co-existing obstructive and central sleep apnea syndrome and periodic breathing. Sleep Med. 2009;10(8):898-903.

82. Dellweg D, Kerl J, Hoehn E, Wenzel M, Koehler D. Randomized controlled trial of noninvasive positive pressure ventilation (NPPV) versus servoventilation in patients with CPAP-induced central sleep apnea (complex sleep apnea). Sleep. 2013;36(8): 1163-71.

83. Javaheri S, Randerath W. Opioids-induced central sleep apnea: mechanisms and therapies. Sleep Med Clin. 2014;9:49-56.

84. Kazimierczak A, Krzyzanowski K, Wierzbowski R, Ryczek R, Smurzynski P, Michalkiewicz D, et al. Resolution of exercise oscillatory ventilation with adaptive servoventilation in patients with chronic heart failure and Cheyne-Stokes respiration: preliminary study. Kardiol Pol. 2011;69(12):1266-71.

85. Sharma BK, Bakker JP, McSharry DG, Desai AS, Javaheri S, Malhotra A. Adaptive servoventilation for treatment of sleepdisordered breathing in heart failure: a systematic review and meta-analysis. Chest. 2012;142(5):1211-21.

86. Galetke W, Ghassemi BM, Priegnitz C, Stieglitz S, Anduleit N, Richter K, et al. Anticyclic modulated ventilation versus continuous positive airway pressure in patients with coexisting obstructive sleep apnea and Cheyne-Stokes respiration: a randomized crossover trial. Sleep Med. 2014;15(8):874-9.

87. Momomura S, Seino Y, Kihara Y, Adachi H, Yasumura Y, Yokoyama H, et al. Adaptive servo-ventilation therapy for patients with chronic heart failure in a confirmatory, multicenter, randomized, controlled study. Circ J. 2015;79(5):981-90.

88. Cowie MR, Woehrle H, Wegscheider K, Angermann C, d'Ortho MP, Erdmann E, et al. Adaptive servo-ventilation for central sleep apnea in systolic heart failure. N Engl J Med. 2015;373(12):1095-105.
89. Cowie MR, Woehrle H, Wegscheider K, Angermann C, d'Ortho MP, Erdmann E, et al. Rationale and design of the SERVE-HF study: treatment of sleep-disordered breathing with predominant central sleep apnoea with adaptive servo-ventilation in patients with chronic heart failure. Eur J Heart Fail. 2013;15(8):937-43.

90. Naughton MT. Cheyne-Stokes respiration: friend or foe? Thorax. 2012;67(4):357-60.

91. Tobin MJ. Mechanical ventilation. N Engl J Med. 1994;330(15): 1056-61.

92. Mezzanotte WS, Tangel DJ, Fox AM, Ballard RD, White DP. Nocturnal nasal continuous positive airway pressure in patients with chronic obstructive pulmonary disease. Influence on waking respiratory muscle function. Chest. 1994;106(4):1100-8.

93. Esteban A, Anzueto A, Frutos F, Alia I, Brochard L, Stewart TE, et al. Characteristics and outcomes in adult patients receiving mechanical ventilation: a 28-day international study. JAMA. 2002;287(3):345-55.

94. Verbraecken J, Willemen M, De Cock W, Van de Heyning P, De Backer WA. Continuous positive airway pressure and lung inflation in sleep apnea patients. Respiration. 2001;68(4):357-64.

95. Manzano F, Fernandez-Mondejar E, Colmenero M, Poyatos ME, Rivera R, Machado J, et al. Positive-end expiratory pressure reduces incidence of ventilator-associated pneumonia in nonhypoxemic patients. Crit Care Med. 2008;36(8):2225-31.

96. Petrof BJ, Legare M, Goldberg P, Milic-Emili J, Gottfried SB. Continuous positive airway pressure reduces work of breathing and dyspnea during weaning from mechanical ventilation in severe chronic obstructive pulmonary disease. Am Rev Respir Dis. 1990;141(2):281-9.

97. Malo J, Ali J, Wood LD. How does positive end-expiratory pressure reduce intrapulmonary shunt in canine pulmonary edema? J Appl Physiol Respir Environ Exerc Physiol. 1984;57(4):1002-10.

98. Smith TC, Marini JJ. Impact of PEEP on lung mechanics and work of breathing in severe airflow obstruction. J Appl Physiol (1985). 1988;65(4):1488-99.

99. de Miguel J, Cabello J, Sanchez-Alarcos JM, Alvarez-Sala R, Espinos D, Alvarez-Sala JL. Long-term effects of treatment with nasal continuous positive airway pressure on lung function in patients with overlap syndrome. Sleep Breath. 2002;6(1):3-10.

100. Tkacova R, Rankin F, Fitzgerald FS, Floras JS, Bradley TD. Effects of continuous positive airway pressure on obstructive sleep apnea and left ventricular afterload in patients with heart failure. Circulation. 1998;98(21):2269-75.

101. Spiesshofer J, Fox H, Lehmann R, Efken C, Heinrich J, Bitter T, et al. Heterogenous haemodynamic effects of adaptive servoventilation therapy in sleeping patients with heart failure and Cheyne-Stokes respiration compared to healthy volunteers. Heart Vessels. 2015. doi:10.1007/s00380-00015-00717-00386. 